\title{
Psychosocial factors are strongly associated with insomnia in users and nonusers of prescribed sleep medication: evidence from the HUNT3 study
}

\author{
This article was published in the following Dove Press journal: \\ Journal of Multidisciplinary Healthcare \\ 19 October 2016 \\ Number of times this article has been viewed
}

\section{Randi Andenæs \\ Sølvi Helseth \\ Nina Misvær \\ Milada C Småstuen \\ Lis Ribu}

Faculty of Health Sciences, Department of Nursing and Health Promotion, Oslo and Akershus University College of Applied Sciences, Oslo, Norway
Correspondence: Randi Andenæs Faculty of Health Sciences, Department of Nursing and Health Promotion, Oslo and Akershus University College of Applied Sciences, Post Box 4, St Olavs plass, N-0130 Oslo, Norway

Tel +47 67236232

Email randi.andenas@hioa.no
Objective: The aim of this study was to examine how neuroticism, stressful life events, selfrated health, life satisfaction, and selected lifestyle factors were related to insomnia both by sex and among users and nonusers of prescribed sleep medication (PSM).

Design: Cross-sectional data from the Norwegian Nord-Trøndelag Health Study (HUNT3, 2006-2008), a population-based health survey, were linked to individual data from the Norwegian Prescription Database.

Methods: Logistic regression analyses were used to investigate the associations between the selected variables and insomnia in both males and females and among subjects using and not using PSM. Individuals were considered to have a presumptive diagnosis of insomnia disorder if they reported difficulty with sleep initiation, sleep maintenance, or early morning awakening several days per week for the last 3 months. PSMs were categorized as anxiolytics or hypnotics; the dose was estimated according to defined daily dose (DDD).

Results: Of the total 50,805 participants, 6,701 (13.2\%) used PSM. The proportions of PSM users were larger among elderly participants. Increased risk of insomnia was strongly associated with poor self-rated health and higher level of neuroticism. These associations were evident for both sexes and were similar among both users and nonusers of PSM. Low satisfaction with life was strongly related to insomnia, but only among nonusers of PSM. Increased doses of PSM were not associated with reduced likelihood of insomnia.

Conclusion: Insomnia is a problem among both users and nonusers of PSM and is associated with psychosocial factors. Our findings suggest that successful treatment for sleep problems should take individual variation into account, such as age, sex, personality traits, satisfaction with life, and health perception.

Keywords: prescription sleep medication, hypnotics, anxiolytics, insomnia, life satisfaction, self-rated health, neuroticism, sex, HUNT

\section{Introduction}

Sleep problems are increasingly recognized as common health problems. ${ }^{1}$ Populationbased estimates suggest that $30 \%$ of the general population has complaints of sleep problems. ${ }^{1}$ Insomnia is the most common type of sleep problem, and it is estimated that $6 \%-15.5 \%$ of the adult population meets the formal diagnostic criteria for clinical insomnia. ${ }^{2,3}$ Insomnia is more commonly reported in females than in males. ${ }^{4}$

Throughout history, people have sought to alleviate sleep problems with various medications and therapies. ${ }^{5}$ In the US, prescriptions of sleep medication from 1993 to 
2007 increased at a rate far higher than sleeplessness complaints and insomnia diagnoses from office-based physician visits. ${ }^{6}$ On the other hand, data from an international survey demonstrated that a large proportion of the participants reporting insomnia were not taking any prescribed sleep medication (PSM). ${ }^{7}$

The 3P or three-factor model for the development and maintenance of insomnia (ie, predisposing, precipitating, and perpetuating factors $)^{8}$ suggests that predisposing factors make some individuals vulnerable to insomnia by lowering the threshold at which sleep disturbances are triggered. One such predisposing factor is the personality trait of neuroticism, characterized by a tendency to perceive the world as threatening, problematic, and distressing. ${ }^{9}$ Many studies have shown that neuroticism is associated with insomnia ${ }^{10-12}$ but have not considered the potentially confounding influence of sleep medication.

Earlier research maintains that critical life events can also cause sleep disruption. ${ }^{13,14}$ Healey et $\mathrm{al}^{13}$ showed that the most frequent stressful events reported by people with insomnia were related to significant losses such as death and divorce and to ill health. Sleep is also affected by health behaviors and lifestyle issues, including physical inactivity, smoking, and alcohol intake, ${ }^{15}$ which can be categorized as perpetuating factors. Few studies have examined how these factors are associated with insomnia by the use of PSM.

Thus, the aim of this study was to investigate how neuroticism, stressful life events, self-rated health, satisfaction with life, and selected life style factors were related to insomnia for both users and nonusers of PSM. An additional aim was to determine whether these associations differed by sex.

\section{Methods \\ Data source}

The Nord-Trøndelag Health Study (HUNT) is one of the largest health studies ever performed. We received crosssectional data from the latest wave (HUNT3), which was carried out from 2006 to 2008. All eligible inhabitants of Nord-Trøndelag, 93,860 people aged 20 years or older, were invited to participate, and 50,805 people were included (54.1\% participation rate). ${ }^{16}$ The participants provided written informed consent to participate in this study, which included permission to link their individual data from the Norwegian Prescription Database (NorPD) ${ }^{17}$ using their unique personal identification number, thereby providing a sample of users and nonusers of PSM that is representative of the general Norwegian population. ${ }^{18,19}$

This study was approved by the Regional Committee for Ethics in Medical Research (2012/2264), the Norwegian
Social Science Data Service (number 35768), the Norwegian Institute of Public Health (permission 14/982), and the HUNT Publication Review Board.

\section{Measures}

\section{Insomnia disorder}

In the HUNT3 questionnaire, the participants were asked how often during the last 3 months they had experienced each of the following three insomnia symptoms: difficulty falling asleep at night, repeatedly waking up during the night, and/or experience of early morning awakening without the ability to return to sleep. The response options were as follows: 1) never/rarely; 2) sometimes; or 3) several days a week. The diagnostic criteria for insomnia disorder using the Diagnostic and Statistical Manual of Mental Disorders, fifth edition, is as follows ${ }^{20}: 1$ ) the predominant complaint must be a difficulty with initiation, maintaining sleep, or early morning awakening (A);2) the complaint must cause clinically significant distress or impairment (B); 3 ) it must occur at least three nights per week (C); 4) it must have been present at least 3 months (D); 5) it must occur despite adequate opportunity for sleep (E); and 6) it must not occur exclusively as a result of another sleep-wake, medical, or mental disorder $(F$ and $H$ ) or as a result of the effects of substance $(G)$. In the present study, the individuals were considered to have a presumptive diagnosis of insomnia disorder if they reported experiencing at least one of the three symptoms several days a week (ie, had a score of 3 on any one item), thus fulfilling criteria A, C, and D. The daytime complaint component (B) was excluded from the insomnia diagnosis mainly because the item from the HUNT3 that could have been used as an indicator of daytime consequences, "How often during the last 3 months have you felt sleepy during the day?", had no specific reference to insomnia as the causal factor and was therefore not considered an accurate or appropriate assessment of the daytime component of insomnia. Criteria $\mathrm{E}-\mathrm{G}$ were not included in the presumptive diagnosis because they could not be evaluated with the available HUNT3 data.

\section{Use of sleep medications}

In Norway, hypnotic and sedative medications are prescribed by clinical doctors. When prescriptions are filled by a pharmacist, the information is sent electronically to the NorPD. Individual data from the NorPD for the 2007 calendar year were merged with the HUNT3 data by the Norwegian Institute of Public Health and the HUNT Research Centre. For the purpose of this analysis, PSMs included those with the following classes and codes of the Anatomical Therapeutic Chemical 
classification system $^{21}$ : benzodiazepine-derivate anxiolytics (N05B A01 diazepam, A04 oxazepam, and A09 clobazam), benzodiazepine-derivate hypnotics (N05C D02 nitrazepam), and Z-drugs (N05C F01 zopiklon and F02 zolpidem). Doses were operationalized as defined daily dose (DDD), which refers to the assumed average maintenance dose per day for a drug used for its main indication in adults. ${ }^{22}$ Three dosing groups were defined based on the following criteria: 1) low ( $\leq 30 \mathrm{DDD})^{23} ; 2$ ) moderate (31-179 DDD); and 3) frequent ( $\geq 180$ DDD). ${ }^{24}$ We defined acquirers of PSMs as users and assumed that the quantity provided was used. Although benzodiazepines have a mix of different pharmacological actions, these medications are all indicated for insomnia. In the regression analyses, anxiolytics and hypnotics were aggregated into one category.

\section{Demographic, psychosocial, and lifestyle factors}

Demographic information included sex, age, and cohabitation status (living alone versus living with others, eg, partner or family member).

The personality trait neuroticism was measured using the Eysenck Personality Questionnaire - Neuroticism Scale (EPQ-N). ${ }^{25}$ The participants responded whether or not they had experienced any of the six symptoms in the questionnaire during the past week (eg, "Do you worry that terrible things might happen?"). The response options were yes or no. A sum score of the number of symptoms with a yes response was computed, with higher scores indicating a higher level of neuroticism. The sum score ranging from 0 to 6 was used as a categorical variable in the descriptive analyses and as a continuous variable in the multivariate models. The Cronbach's alpha for the EPQ-N was 0.75 for medication users and 0.72 for nonusers.

Satisfaction with life was measured by a single global item: "Thinking about how you are feeling at the moment, are you mostly satisfied with life or are you mostly dissatisfied?" The participants responded using a 7-point Likert scale: 1) "very satisfied"; 2) "satisfied"; 3) "somewhat satisfied"; 4) "neither satisfied nor dissatisfied"; 5) "somewhat dissatisfied"; 6) "dissatisfied"; and 7) "very dissatisfied". ${ }^{26}$ The scale was recoded to four categories by merging categories 4-7, due to few responses in these categories.

Self-rated health was assessed with the question "Overall, how is your health at the moment?", with four response categories ranging from "poor" to "very good".

Stressful life events in the last 12 months were assessed with two questions: "Has a member of your close family died? (child, spouse/partner, sibling or parent)" and "Has your relationship with your spouse or long-term partner ended?". The response options were yes or no.

The frequency of physical activity was reported as less than once a week, once a week, two to three times a week, or daily. Current smoking habits were categorized as either nonsmoker (never smoked or former smoker) or current smoker (daily or occasionally). Alcohol use was measured as liters of alcohol consumed per year. ${ }^{27}$

\section{Statistical analyses}

Data were described with median and range for continuous variables because the majority of continuous variables were not normally distributed and with frequencies and percentages for categorical data. The prevalence of insomnia was calculated as the proportion of individuals with sleep problems (as defined above), and the estimate was presented with 95\% confidence interval (CI). The crude differences between sexes were assessed using chi-square tests, $t$-tests, or MannWhitney $U$ tests (for nonnormally distributed variables). The associations between insomnia and selected variables were analyzed using univariate and multivariate logistic regression models. The multiple models were stratified by sex and were fit separately for sleep medication users and nonusers. The strength of associations is presented as odds ratios with $95 \%$ CIs and $P$-values. To correct for multiple testing, $P$-values $<0.01$ were considered statistically significant. All statistical analyses were carried out using SPSS Version 22.0 for Windows (IBM Corporation, Armonk, NY, USA). ${ }^{28}$

\section{Results}

Of 50,805 participants included in HUNT3 (age range 19-100 years $), 5.6 \%(n=2,861)$ met the diagnostic criteria for insomnia during the prior 3 months; $6.8 \%$ were females and $4.2 \%$ were males. Of these, $13.2 \%(n=6,701)$ used PSM at least once during 2007 (17.2\% females and 8.4\% males). The percentages of individuals with insomnia who were nonusers of PSM were $68 \%$ of females and $79 \%$ of males.

\section{Participant characteristics of users of PSM}

The majority of users of PSM were female (71.2\%). Of the female users, $12.5 \%$ had insomnia, compared to $10.4 \%$ of the male users (Table 1). The female users had higher neuroticism scores than the male users; the median EPQ-N score was 3 for the female users and 2 for the male users. In addition, $23.3 \%$ of the female users and $26.4 \%$ of the male users of PSM were not satisfied with their life and $3.8 \%$ of the female users versus $5.1 \%$ of male users rated their health as 
Table I Sample characteristics of sleep medication users and nonusers

\begin{tabular}{|c|c|c|c|c|c|c|}
\hline \multirow[t]{2}{*}{ Characteristic } & \multicolumn{2}{|l|}{ Users } & \multirow[t]{2}{*}{$P$-value } & \multicolumn{2}{|l|}{ Nonusers } & \multirow[t]{2}{*}{$P$-value } \\
\hline & $\begin{array}{l}\text { Female }(n=4,774) \text {, } \\
\%(n)\end{array}$ & $\begin{array}{l}\text { Male }(n=I, 927), \\
\%(n)\end{array}$ & & $\begin{array}{l}\text { Female }(n=22,982), \\
\%(n)\end{array}$ & $\begin{array}{l}\text { Male }(n=21, \mid 22) \\
\%(n)\end{array}$ & \\
\hline Insomnia & & & 0.001 & & & $<0.001$ \\
\hline No & $87.5(4,175)$ & $89.6(I, 727)$ & & $94.4(21,692)$ & $96.3(20,350)$ & \\
\hline Yes & $12.5(599)$ & $10.4(200)$ & & $5.6(1,290)$ & $3.7(772)$ & \\
\hline Age, years (in categories) & & & 0.863 & & & $<0.001$ \\
\hline$<29$ & I.6 (76) & I.7 (33) & & II. $2(2,570)$ & $8.7(I, 833)$ & \\
\hline $30-39$ & $4.5(2 \mid 4)$ & $4.4(84)$ & & $16.5(3,793)$ & I3.I $(2,770)$ & \\
\hline $40-49$ & $11.2(533)$ & II.I (2I3) & & $21.4(4,915)$ & $20.6(4,352)$ & \\
\hline $50-59$ & $21.3(1,016)$ & $22.0(423)$ & & $21.7(4,986)$ & $23.7(5,000)$ & \\
\hline $60-69$ & $25.7(1,226)$ & $24.5(473)$ & & $17.0(3,902)$ & $19.9(4,201)$ & \\
\hline $70-79$ & $22.6(1,079)$ & $22.1(425)$ & & $8.7(2,008)$ & $10.6(2,242)$ & \\
\hline$\geq 80$ & $13.2(630)$ & $14.3(276)$ & & $3.5(808)$ & $3.4(724)$ & \\
\hline \multicolumn{7}{|l|}{ Neuroticism (EPQ-N) } \\
\hline 0 & $12.2(583)$ & $16.9(325)$ & $<0.001$ & $24.9(5,72 I)$ & $33.5(7,082)$ & $<0.001$ \\
\hline 1 & I3.3 (633) & I 4.0 (269) & & I9.I $(4,389)$ & $17.5(3,698)$ & \\
\hline 2 & $12.8(613)$ & $12.6(243)$ & & $13.4(3,09 \mid)$ & $10.8(2,285)$ & \\
\hline 3 & $12.4(593)$ & II.4 (219) & & $9.9(2,27 \mathrm{I})$ & $6.5(1,363)$ & \\
\hline 4 & II.3 (54I) & $9.1(176)$ & & $6.5(1,493)$ & $3.8(806)$ & \\
\hline 5 & $10.8(5 \mid 7)$ & $8.3(159)$ & & $4.6(1,050)$ & $2.3(488)$ & \\
\hline 6 & $8.1(389)$ & $5.3(103)$ & & $2.7(6 \mathrm{II})$ & I.2 (247) & \\
\hline Missing & $19.0(905)$ & $22.5(433)$ & & $18.9(4,355)$ & $24.4(5,153)$ & \\
\hline Death of a close family member & & & 0.067 & & & 0.215 \\
\hline No & $79.4(3,791)$ & $82.0(1,580)$ & & $88.6(20,354)$ & $89.1(18,812)$ & \\
\hline Yes & $16.3(777)$ & $14.6(282)$ & & $9.5(2,185)$ & $9.2(1,939)$ & \\
\hline Missing & & & & $1.9(443)$ & $1.8(37 I)$ & \\
\hline Relationship breakup & & & 0.068 & & & 0.149 \\
\hline No & $83.4(3,980)$ & $82.9(1,598)$ & & $88.4(20,317)$ & $88.4(18,670)$ & \\
\hline Yes & $12.4(59 \mid)$ & $14.2(274)$ & & $9.5(2,192)$ & $10.0(2,110)$ & \\
\hline Missing & $4.3(203)$ & $2.9(55)$ & & $2.1(473)$ & $1.6(342)$ & \\
\hline \multicolumn{7}{|l|}{ Lives with partner/others } \\
\hline No & $46.7(2,230)$ & $38.7(745)$ & $<0.001$ & $35.9(8,245)$ & $36.2(7,650)$ & 0.455 \\
\hline Yes & $53.3(2,544)$ & $61.3(1,182)$ & & $64.1(14,737)$ & $63.8(13,472)$ & \\
\hline Physical activity & & & 0.005 & & & $<0.001$ \\
\hline Less than once a week & $21.1(1,008)$ & $25.2(485)$ & & $16.5(3,789)$ & $26.9(5,688)$ & \\
\hline Once a week & $18.3(874)$ & $16.6(319)$ & & $2 I . I(4,84 I)$ & $22.2(4,694)$ & \\
\hline Two to three times a week & $36.1(1,723)$ & 35.2 (679) & & $4 I .8(9,6 \mid 2)$ & $33.9(7,158)$ & \\
\hline Daily & $20.9(996)$ & $20.2(389)$ & & $18.9(4,344)$ & $15.5(3,275)$ & \\
\hline Missing & $3.6(173)$ & $2.9(55)$ & & $1.7(396)$ & $1.5(307)$ & \\
\hline Current smoking status & & & $<0.001$ & & & $<0.001$ \\
\hline Nonsmoker & $66.3(3,163)$ & $69.7(1,343)$ & & $73.0(16,788)$ & $75.2(15,872)$ & \\
\hline Smoker & $28.9(I, 38 I)$ & $26.5(510)$ & & $24.3(5,591)$ & $22.4(4,726)$ & \\
\hline Missing & $4.8(230)$ & $3.8(74)$ & & $2.6(603)$ & $2.5(521)$ & \\
\hline Alcohol use (L/yr) & & & $<0.001$ & & & $<0.001$ \\
\hline Median (range) & $0.75(0-24.6)$ & $1.54(0-24.6)$ & & $0.78(0-36.9)$ & I.65 (0-59.2) & \\
\hline Missing & $20.2(80 I)$ & $12.6(216)$ & & $8.8(2,023)$ & $6.2(1,235)$ & \\
\hline Satisfaction with life & & & $<0.001$ & & & $<0.001$ \\
\hline Very satisfied & 13.7 (652) & I I.8 (227) & & $21.6(4,955)$ & $20.9(4,406)$ & \\
\hline Satisfied & $25.9(1,238)$ & $26.2(504)$ & & $37.5(8,610)$ & $37.9(7,995)$ & \\
\hline Somewhat satisfied & $35.3(1,687)$ & $33.9(653)$ & & $28.4(6,52 I)$ & $29.5(6,234)$ & \\
\hline$<$ Somewhat satisfied & $23.3(1,110)$ & $26.4(508)$ & & II $.4(2,573)$ & $10.5(2,218)$ & \\
\hline Missing & $1.8(87)$ & $1.8(35)$ & & I.4 (323) & $1.3(269)$ & \\
\hline Self-rated health & & & 0.030 & & & $<0.001$ \\
\hline Poor & $3.8(183)$ & $5.1(99)$ & & $0.9(210)$ & I.I (226) & \\
\hline Fair & $46.9(2,239)$ & $44.5(857)$ & & $21.7(4,981)$ & $19.3(4,077)$ & \\
\hline Good & $40.9(1,952)$ & 43.0 (829) & & $56.5(12,979)$ & $60.6(12,810)$ & \\
\hline Very good & $3.8(183)$ & $4.2(8 I)$ & & $17.6(4,043)$ & $16.5(3,49 \mid)$ & \\
\hline Missing & $4.5(217)$ & $3.2(6 I)$ & & $3.3(769)$ & $2.5(5 \mid 8)$ & \\
\hline
\end{tabular}

Abbreviations: EPQ-N, Eysenck Personality Questionnaire - Neuroticism Scale. 
poor. Table 1 also lists the proportion of each age group who used PSM. The highest proportion of users were participants between 60 years and 69 years, where approximately one of four were PSM users. Approximately one-third of both males and females used a combination of anxiolytics and hypnotics (Table 2). For hypnotics, frequent doses (DDD $\geq 180$ ) were most common, while for anxiolytics, the majority of users were prescribed low doses ( $\leq 30 \mathrm{DDD})$.

\section{Associations with insomnia in users of PSM}

In multivariate logistic regression analyses (Table 3), our data suggest that in older age, better self-rated health was associated with a lower risk of insomnia and higher levels of neuroticism were associated with a higher risk of insomnia for both sexes of PSM users. The medication dose was not significantly associated with insomnia for either sex. Similarly, satisfaction with life, smoking, alcohol use, living situation, stressful life events (death in the family or relationship breakup), and exercise frequency were not associated with insomnia for either sex.

\section{Participant characteristics of nonusers of PSM}

As shown in Table $1,5.6 \%$ of the females and $3.7 \%$ of the males without PSM met the criteria for insomnia. The median

Table 2 Use of PSM by sex and dose

\begin{tabular}{|c|c|c|c|c|}
\hline Sex & Dose (DDD) & Anxiolytics, \% (n) & Hypnotics, \% (n) & Combined, \% (n) \\
\hline \multirow[t]{4}{*}{ Females } & Low $(1-30)$ & $58.5(1,184)$ & $24.9(894)$ & $32.2(1,537)$ \\
\hline & Moderate (3I-I79) & $31.1(629)$ & $34.4(1,237)$ & $33.6(1,602)$ \\
\hline & Frequent $(\geq 180)$ & $10.4(211)$ & $40.7(1,463)$ & $34.2(1,635)$ \\
\hline & Total & $100(2,024)$ & $100(3,594)$ & $100(4,774)$ \\
\hline \multirow[t]{4}{*}{ Males } & Low (1-30) & $56.1(464)$ & $28.8(399)$ & $35.6(686)$ \\
\hline & Moderate (3|-|79) & $30.0(248)$ & $29.9(4 \mid 3)$ & $29.3(565)$ \\
\hline & Frequent $(\geq 180)$ & $13.9(\mid 15)$ & $4 I .3(57 I)$ & $35.1(676)$ \\
\hline & Total & $100(827)$ & $100(1,383)$ & $100(I, 927)$ \\
\hline
\end{tabular}

Abbreviations: PSM, prescribed sleep medication; DDD, defined daily dose.

Table 3 Logistic regression analysis of personality and lifestyle predictors of insomnia (dependent variable) among users of PSM

\begin{tabular}{|c|c|c|c|c|c|c|}
\hline \multirow[t]{2}{*}{ Variables } & \multicolumn{3}{|c|}{ Females } & \multicolumn{3}{|l|}{ Males } \\
\hline & OR & $95 \% \mathrm{Cl}$ & $P$-value & OR & $95 \% \mathrm{Cl}$ & $P$-value \\
\hline Age & 1.47 & $1.35-1.6 \mathrm{I}$ & $<0.001$ & 1.40 & $1.22-1.59$ & $<0.001$ \\
\hline \multicolumn{7}{|l|}{ Self-reported health (ref = very good) } \\
\hline Fairly good & 2.04 & $1.28-3.22$ & 0.003 & 2.50 & $1.32-4.76$ & 0.005 \\
\hline Good & 4.00 & $2.50-6.66$ & $<0.001$ & 4.76 & $2.27-10.00$ & $<0.001$ \\
\hline Poor & 5.55 & $2.44-14.26$ & $<0.001$ & II.II & $2.13-50.00$ & 0.004 \\
\hline Neuroticism (EPQ-N) & 1.26 & $1.19-1.34$ & $<0.001$ & 1.29 & $1.16-1.43$ & $<0.001$ \\
\hline \multicolumn{7}{|l|}{ Sleep medication dose $(r e f=l o w)$} \\
\hline Moderate & 1.16 & $0.89-1.50$ & 0.275 & 1.39 & $0.90-2.14$ & 0.137 \\
\hline Frequent & 1.17 & $0.89-1.55$ & 0.257 & 0.63 & $0.39-1.01$ & 0.058 \\
\hline \multicolumn{7}{|l|}{ Satisfaction with life (ref = very satisfied) } \\
\hline Satisfied & 1.17 & $0.74-1.86$ & 0.509 & 1.30 & $0.54-3.18$ & 0.560 \\
\hline Somewhat satisfied & 1.36 & $0.87-2.11$ & 0.172 & 1.26 & $0.53-3.01$ & 0.600 \\
\hline Less than somewhat satisfied & 1.73 & $1.09-2.75$ & 0.020 & 1.64 & $0.68-3.99$ & 0.271 \\
\hline Smoking (ref = nonsmoker) & 0.96 & $0.76-1.21$ & 0.718 & 0.97 & $0.64-1.46$ & 0.873 \\
\hline Alcohol use (L/yr) & 1.05 & $0.99-1.11$ & 0.094 & 1.00 & $0.93-1.06$ & 0.951 \\
\hline Living with others (ref $=$ living alone) & 1.01 & $0.79-1.29$ & 0.936 & 0.80 & $0.52-1.23$ & 0.311 \\
\hline Death in the family (ref $=$ no death) & 1.08 & $0.8 \mathrm{I}-\mathrm{I} .44$ & 0.606 & 1.13 & $0.68-1.87$ & 0.629 \\
\hline Relationship breakup (ref = no breakup) & 1.19 & $0.88-1.61$ & 0.267 & 1.00 & $0.60-1.65$ & 0.992 \\
\hline \multicolumn{7}{|l|}{ Exercise (ref $=$ less than once a week) } \\
\hline Once a week & 0.87 & $0.63-1.20$ & 0.387 & 0.78 & $0.46-1.32$ & 0.347 \\
\hline Two to three times a week & 0.77 & $0.58-1.02$ & 0.070 & 0.62 & $0.39-0.97$ & 0.036 \\
\hline Daily & 0.78 & $0.56-1.08$ & 0.133 & 0.55 & $0.31-0.97$ & 0.037 \\
\hline
\end{tabular}

Note: Bold values are statistically significant.

Abbreviations: PSM, prescribed sleep medication; OR, odds ratio; Cl, confidence interval; EPQ-N, Eysenck Personality Questionnaire - Neuroticism Scale; ref, reference group; yr, year. 
score for neuroticism (EPQ-N) was 1 for both sexes of PSM nonusers. Approximately $10 \%$ of PSM nonusers $(11.4 \%$ of females and $10.5 \%$ of males) reported low satisfaction with life, and when evaluating their own health, $0.9 \%$ of the female nonusers versus $1.1 \%$ of the male nonusers rated their health as poor.

\section{Associations with insomnia in nonusers of PSM}

As with users of PSM, older age and higher levels of neuroticism (EPQ-N) were significantly associated with increased risk of insomnia among both male and female nonusers of PSM, and better self-rated health reduced risk (Table 4). Unlike for the PSM users, low satisfaction with life was the strongest predictor of insomnia among both male and female nonusers of PSM, with the least satisfied participants being more than twice as likely to report insomnia than the very satisfied participants. Alcohol use and stressful life events (ie, relationship breakup) were also borderline significant $(P<0.02)$ with increased insomnia risk among male nonusers, but no association among female nonusers. Exercise was associated with significantly reduced risk of insomnia in the female nonusers, but not among male nonusers. The female nonusers who reported exercising more than once a week had a lower risk of insomnia than those who reported no exercise. As for the PSM users, smoking and living situation were not significantly associated with insomnia risk for either sex of PSM nonusers.

\section{Discussion}

In the present study, we found that increased risk of insomnia was strongly associated with psychosocial factors such as higher levels of neuroticism and poorer self-rated health. These associations were similar for both sexes and in both users and nonusers of PSM. Furthermore, lower life satisfaction was strongly related to insomnia, but only among nonusers of PSM. Somewhat surprisingly, more frequent doses of PSM were not associated with reduced risk of insomnia.

Neuroticism represents a person's tendency to worry and feel nervous, as opposed to feeling relaxed and safe. ${ }^{29}$ Several previous studies have shown that neuroticism is associated with insomnia, ${ }^{10-12}$ but our data demonstrate this association both in users and nonusers of PSM. Individuals with high neuroticism might feel that they need sleep medication to calm down, reduce sleep latency, and stay asleep at night.

Previous research has shown that poor sleep and reduced quality of life are related ${ }^{30-32}$ and that life satisfaction contributes to favorable sleep. ${ }^{31}$ It is worth noting that $68 \%$ of

Table 4 Logistic regression analysis of personality and life style predictors of insomnia (dependent variable) among nonusers of PSM

\begin{tabular}{|c|c|c|c|c|c|c|}
\hline \multirow[t]{2}{*}{ Variables } & \multicolumn{3}{|c|}{ Females } & \multicolumn{3}{|c|}{ Males } \\
\hline & OR & $95 \% \mathrm{Cl}$ & $P$-value & OR & $95 \% \mathrm{Cl}$ & $P$-value \\
\hline Age & 1.30 & $1.25-1.37$ & $<0.001$ & 1.12 & $1.05-1.19$ & $<0.001$ \\
\hline \multicolumn{7}{|l|}{ Self-reported health (ref $=$ very good) } \\
\hline Fairly good & 1.30 & $0.83-2.00$ & 0.254 & 1.56 & $0.98-2.50$ & 0.060 \\
\hline Good & 3.12 & 4.76-5.55 & $<0.001$ & 3.45 & $2.17-5.55$ & $<0.001$ \\
\hline Poor & 4.76 & $7.69-2.94$ & $<0.001$ & 5.88 & $3.23-10.00$ & $<0.001$ \\
\hline Neuroticism (EPQ-N) & 1.38 & $1.33-1.43$ & $<0.001$ & 1.47 & $1.40-1.54$ & $<0.001$ \\
\hline \multicolumn{7}{|l|}{ Satisfaction with life (ref = very satisfied) } \\
\hline Satisfied & 1.04 & $0.83-1.30$ & 0.710 & 1.24 & $0.91-1.69$ & 0.175 \\
\hline Somewhat satisfied & $\mathbf{1 . 4 I}$ & $1.13-1.76$ & 0.002 & 1.64 & $1.21-2.22$ & 0.002 \\
\hline Less than somewhat satisfied & 2.08 & $1.63-2.65$ & $<0.001$ & 2.19 & $1.56-3.06$ & $<0.001$ \\
\hline Smoking (ref = nonsmoker) & 1.09 & $0.94-1.25$ & 0.264 & 0.89 & $0.73-1.08$ & 0.237 \\
\hline Alcohol use $(\mathrm{L} / \mathrm{yr})$ & 0.98 & $0.95-1.03$ & 0.489 & 1.03 & $1.00-1.06$ & 0.013 \\
\hline Living with others (ref $=$ living alone) & 1.03 & $0.88-1.21$ & 0.707 & 1.05 & $0.85-1.29$ & 0.654 \\
\hline Death in the family (ref $=$ no death) & 1.24 & $1.00-1.53$ & 0.055 & 0.81 & $0.6 \mathrm{I}-1.09$ & 0.164 \\
\hline Relationship breakup (ref $=$ no breakup) & 0.87 & $0.7 \mathrm{I}-1.08$ & 0.205 & 1.35 & $1.06-1.71$ & 0.015 \\
\hline \multicolumn{7}{|l|}{ Exercise (ref $=$ less than once a week) } \\
\hline Once a week & 0.86 & $0.70-1.04$ & 0.111 & 1.00 & $0.80-1.25$ & 0.972 \\
\hline Two to three times a week & 0.32 & $0.2|-0.5|$ & $<0.001$ & 1.02 & $0.83-1.26$ & 0.809 \\
\hline Daily & 0.21 & $0.13-0.34$ & $<0.001$ & 1.00 & $0.77-1.30$ & 0.987 \\
\hline
\end{tabular}

Note: Bold values are statistically significant.

Abbreviations: PSM, prescribed sleep medication; OR, odds ratio; Cl, confidence interval; ref, reference group; EPQ-N, Eysenck Personality Questionnaire - Neuroticism Scale; yr, year. 
females and $79 \%$ of males with insomnia in the HUNT3 were nonusers of PSM. In the nonusers group only, low satisfaction with life was associated with an increased risk of insomnia and was the strongest of the included predictors. There is little research on the attitudes of people who might use or refrain from using sleep medication; therefore, speculation about this relationship is difficult. However, our results support earlier research, emphasizing the small proportion of individuals who seek professional help for their insomnia. ${ }^{7,33}$

Good sleep is required for both good quality of life and good health. ${ }^{34}$ For both users and nonusers of PSM, those who rated their health as good or very good had a lower risk of having insomnia. Previous population-based studies have reached similar conclusions. ${ }^{35-37}$ The concept of "self-rated health" likely captures a wide array of medical diseases or health complaints, many of which may cause insomnia. ${ }^{38}$ Costa and $\mathrm{McCrae}^{29}$ suggested that individuals with high levels of neuroticism could have a tendency to overreport negative health conditions. Underlying medical causes were not examined in our study, but should be taken into consideration in clinical practice.

The present study revealed a protective effect of daily regular exercise on insomnia, but only for the female nonusers of PSM. However, multiple studies have demonstrated significant improvements in subjective sleep quality with exercise interventions; a systematic review of six randomized trials of exercise in middle-aged and older adults (with and without insomnia) demonstrated improvements in sleep quality and decreased sleep medication use ${ }^{39}$ Furthermore, in a randomized controlled trial, increasing physical activity to the minimum level recommended in public health guidelines was shown to improve both daytime and nighttime symptoms in inactive adults with insomnia. ${ }^{40}$ The lack of association between physical activity and insomnia among the PSM users in the current study could be attributed to low reliability of self-report physical activity measures.

We also found some sex differences in this populationbased study. As reported in other European epidemiological studies, insomnia symptoms were more frequent in females than in males. ${ }^{41,42}$ Logistic regression showed that neuroticism was associated with a higher risk of insomnia for males compared to females, and the effect was even more pronounced in males who did not use PSM. Similar to previous studies, ${ }^{7,32}$ females were more likely than males to use pharmacotherapy for sleep problems, and they were more likely to report symptoms consistent with insomnia. One interpretation of these findings is that males have a higher threshold for consulting their doctor about sleep medication, even if they have a plausible need. There is consistent evidence that males have less frequent primary care consultations than females, ${ }^{43}$ and Kapur et $\mathrm{al}^{44}$ found that factors related to psychological distress seemed to be more important as determinants for consultations among females, whereas physical symptoms and cognitive factors were more important among males. Furthermore, data from a large US survey on individuals who received treatment for sleep difficulties showed that among visits where pharmacotherapy was prescribed, visits by male patients were $39 \%$ less likely than visits by female patients to result in a prescription for a medication with abuse potential. ${ }^{45}$ Sex issues in insomnia treatment, pharmacological as well as nonpharmacological, warrant further study.

A relatively large proportion of our sample (13.2\%) received PSM, and one-third was categorized as frequent users. Not surprisingly, risk of insomnia, as well as sleep medication use, was higher in older and elderly adults. Earlier research has shown that increased use of PSM among older adults may be attributable to divorce/relationship breakup ${ }^{46}$ and to hormonal changes among females. ${ }^{36}$ It could also mean that the elderly are more often prescribed medication for sleep problems, or alternatively, are less afraid to use sleep medications because they are less concerned about the potential side effects or drug dependency. Previous research has called attention to the high rate of sleep medication use among the elderly as a cause for concern. ${ }^{47,48}$ In the present study, more frequent doses of sleep medication did not seem to have any effect on insomnia risk. The association between neuroticism and insomnia was strong, and since personality traits are considered to be relatively stable over time, ${ }^{29}$ this stability might help explain why using PSM does not alter the association between PSM and insomnia. Furthermore, the prevalence of insomnia was actually higher in individuals who received PSM than in PSM nonusers, thus indicating that insomnia is a persistent problem and that sleep medication is not a solution or cure of insomnia, but more of a temporary relief.

\section{Strengths and weaknesses}

The design of our study was cross-sectional; hence, we were not able to perform a direct comparison between users and nonusers of PSM with regard to better or worse sleep outcome nor does this design permit drawing any conclusions about cause and effect. Such comparison would only be possible with a randomized controlled trial. To answer the question of whether improvement in sleep positively impacts health and life satisfaction, longitudinal studies designed to examine 
causality are needed. Such studies should also include objective verification of sleep length and sleep quality.

The strengths of the study are the relatively large sample size of home-dwelling persons with a wide age range and the linkage to the NorPD giving precise data on the type and quantity of sleep medication received during the previous year, instead of relying on the participant's memory. A general weakness in studies based on data from NorPD is that the dispensed prescription serves as a proxy for the amount of medication consumed. As such, the medication is not necessarily used by the recipient. Furthermore, our sample includes relatively few male users of sleep medication. Since our estimates are based on limited numbers, the precision is low.

\section{Consequences for clinical practice}

Psychosocial factors were related to insomnia, and more frequent doses of sleep medication did not seem to have any effect. In France, the significant dependence and abuse potential for Z-drugs have recently been highlighted. ${ }^{49}$ Proven nondrug treatments exist, such as cognitive behavioral therapy and sleep hygiene education. ${ }^{50}$ Our findings suggest that successful treatment for sleep problems should take individual variation into account, such as age, sex, personality traits, and health perception. Moreover, there is a need for more public education about sleep and broader dissemination of evidence-based therapies for insomnia. ${ }^{51}$ Such therapies should be made more easily accessible for individuals experiencing sleep problems, eg, from web-based programs. ${ }^{52}$

\section{Conclusion}

Insomnia is a problem among both users and nonusers of PSM and is associated with psychosocial factors. Our findings suggest that successful treatment for sleep problems should take individual variation into account, such as age, sex, personality traits, satisfaction with life, and health perception.

\section{Acknowledgments}

The third survey of the Nord-Trøndelag Health Study 2006-2008 (HUNT3) was a collaboration between the HUNT Research Centre (Faculty of Medicine, Norwegian University of Science and Technology), Nord-Trøndelag County Council, Central Norway Regional Health Authority, and NorPD. This study was supported by internal funding from the Department of Nursing and Preventive Healthcare, Oslo and Akershus University College of Applied Sciences.

\section{Disclosure}

The authors report no conflicts of interest in this work.

\section{References}

1. National Institutes of Health. National Institutes of Health State of the Science Conference statement on manifestations and management of chronic insomnia in adults, June 13-15, 2005. Sleep. 2005;28(9):1049-1057.

2. Ohayon MM, Bader G. Prevalence and correlates of insomnia in the Swedish population aged 19-75 years. Sleep Med. 2010;11(10):980-986.

3. Pallesen S, Sivertsen B, Nordhus IH, Bjorvatn B. A 10-year trend of insomnia prevalence in the adult Norwegian population. Sleep Med. 2014;15(2):173-179.

4. Lichstein KLT, Daniel J, McCrae CS. Insomnia: epidemiology and risk factors. In: Kryger MH, Thomas R, Dement WC, editors. Principles and Practice of Sleep Medicine. 5th ed. St. Louis, MI: Elsevier Saunders; 2011:827-838.

5. Neubauer DN. New and emerging pharmacotherapeutic approaches for insomnia. Int Rev Psychiatry. 2014;26(2):214-224.

6. Moloney ME, Konrad TR, Zimmer CR. The medicalization of sleeplessness: a public health concern. Am J Public Health. 2011;101(8): 1429-1433.

7. Leger D, Poursain B. An international survey of insomnia: underrecognition and under-treatment of a polysymptomatic condition. Curr Med Res Opin. 2005;21(11):1785-1792.

8. Spielman AJ, Caruso LS, Glovinsky PB. A behavioral perspective on insomnia treatment. Psychiatr Clin North Am. 1987;10(4):541-553.

9. Eysenck HJ. Dimensions of Personality. London: Routledge \& Kegan Paul; 1948.

10. Kales A, Caldwell AB, Soldatos CR, Bixler EO, Kales JD. Biopsychobehavioral correlates of insomnia. II. Pattern specificity and consistency with the Minnesota Multiphasic Personality Inventory. Psychosom Med. 1983;45(4):341-356.

11. van de Laar M, Verbeek I, Pevernagie D, Aldenkamp A, Overeem S. The role of personality traits in insomnia. Sleep Med Rev. 2010;14(1):61-68.

12. Hintsanen M, Puttonen S, Smith K, et al. Five-factor personality traits and sleep: evidence from two population-based cohort studies. Health Psychol. 2014;33(10):1214-1223.

13. Healey ES, Kales A, Monroe LJ, Bixler EO, Chamberlin K, Soldatos CR. Onset of insomnia: role of life-stress events. Psychosom Med. 1981;43(5):439-451.

14. Riemann D, Spiegelhalder K, Feige B, et al. The hyperarousal model of insomnia: a review of the concept and its evidence. Sleep Med Rev. 2010;14(1):19-31.

15. Strine TW, Chapman DP. Associations of frequent sleep insufficiency with health-related quality of life and health behaviors. Sleep Med. 2005;6(1):23-27.

16. Krokstad S, Langhammer A, Hveem K, et al. Cohort profile: the HUNT Study, Norway. Int J Epidemiol. 2013;42(4):968-977.

17. Norwegian Prescription Database (NorPD), Norwegian Institute of Public Health. 2016. Available from: https://www.fhi.no/en/hn/healthregistries/norpd/. Accessed September 9, 2016.

18. Holmen J, Midthjell K. The Nord-Trøndelag health study 1995-97 (HUNT 2): objectives, contents, methods and participation. Norsk Epidemiol. 2003;13:19-22.

19. Langhammer A, Krokstad S, Romundstad P, Heggland J, Holmen J. The HUNT study: participation is associated with survival and depends on socioeconomic status, diseases and symptoms. BMCMed Res Methodol. 2012;12:143.

20. American Psychiatric Association. Diagnostic and Statistical Manual of Mental Disorders: DSM-5. 5th ed. Washington, DC: American Psychiatric Association; 2013.

21. WHO Collaborating Centre for Drug Statistics Metodology [homepage on the Internet]. International language for drug utilization research; 2016. Oslo: Norwegian Institute of Public Health [updated May 19, 2016; cited September 28, 2015]. Available from: http://www.whocc.no/. Accessed June 22, 2016.

22. WHO Collaborating Centre for Drug Statistics Metodology [webpage on the Internet]. ACT/DDD Index; 2015. Oslo: Norwegian Institute of Public Health [updated December 16, 2015; cited October 29, 2015]. Available from: http://www.whocc.no/atc_ddd_index/. Accessed June 22, 2016. 
23. Helsedirektoratet. Nasjonal faglig veileder vanedannende legemidler rekvirering og forsvarlighet. Vanedannende sovemedisin [National Specialist Guideline for Addictive Medicine-Requisition and Propriety. Addictive Sleep Medication]. Oslo: The Health Directorate. [Updated December 14, 2015; cited January 26, 2016]. Available from: https:// helsedirektoratet.no/Retningslinjer/Vanedannende\%20legemidler.pdf. Accessed January 26, 2015.

24. Fang S-Y, Chen C-Y, Chang IS, Wu EC-H, Chang C-M, Lin K-M. Predictors of the incidence and discontinuation of long-term use of benzodiazepines: a population-based study. Drug Alcohol Depend. 2009;104(1-2):140-146.

25. Eysenck SBG, Tambs K. Cross-cultural comparison of personality: Norway and England. Scand J Psychol. 1990;31(3):191-197.

26. Pavot W, Diener E. The satisfaction with life scale and the emerging construct of life satisfaction. J Posit Psychol. 2008;3(2):137-152.

27. Støver M, Bratberg G, Nordfjærn T, Krokstad S. Bruk av alkohol og medikamenter blant eldre (60+) i Norge. Helseundersøkelsen i NordTrøndelag [Use of Alcohol and Prescription Drugs among Elderly (60+) in Norway. The HUNT Study, Norway]. HUNT forskningssenter, NTNU: NTNU; 2012.

28. SPSS [computer program]. Version 22: Armonk, NY: IBM Corporation; 2016.

29. Costa PT Jr, McCrae RR. Neuroticism, somatic complaints, and disease: is the bark worse than the bite? J Pers. 1987;55(2):299-316.

30. Paunio T, Korhonen T, Hublin C, et al. Longitudinal study on poor sleep and life dissatisfaction in a nationwide cohort of twins. Am J Epidemiol. 2009;169(2):206-213.

31. Brand S, Beck J, Hatzinger M, Harbaugh A, Ruch W, Holsboer-Trachsler E. Associations between satisfaction with life, burnout-related emotional and physical exhaustion, and sleep complaints. World J Biol Psychiatry. 2010;11(5):744-754.

32. Omvik S, Pallesen S, Bjorvatn B, Sivertsen B, Havik OE, Nordhus IH. Patient characteristics and predictors of sleep medication use. Int Clin Psychopharmacol. 2010;25(2):91-100.

33. Morin CM, Leblanc M, Daley M, Gregoire JP, Mérette C. Epidemiology of insomnia: prevalence, self-help treatments, consultations, and determinants of help-seeking behaviors. Sleep Med. 2006;7(2):123-130.

34. Kyle S, Espie C, Morgan K. “... Not just a minor thing, it is something major, which stops you from functioning daily": quality of life and daytime functioning in insomnia. Behav Sleep Med. 2010;8(3):123-140.

35. Roth T, Coulouvrat C, Hajak G, et al. Prevalence and perceived health associated with insomnia based on DSM-IV-TR; International Statistical Classification of Diseases and Related Health Problems, Tenth Revision; and Research Diagnostic Criteria/International Classification of Sleep Disorders, Second Edition criteria: results from the America Insomnia Survey. Biol Psychiatry. 2011;69(6):592-600.

36. Vaidya V, Gabriel MH, Gangan N, Borse M. Characteristics of prescription and nonprescription sleep medication users in the United States. Popul Health Manag. 2014;17(6):345-350.
37. Ohida T, Kamal A, Uchiyama M, et al. The influence of lifestyle and health status factors on sleep loss among the Japanese general population. Sleep. 2001;24(3):333-338.

38. Sivertsen B, Nordhus IH, Bjorvatn B, Pallesen S. Sleep problems in general practice: a national survey of assessment and treatment routines of general practitioners in Norway. J Sleep Res. 2010;19(1 pt 1):36-41.

39. Yang P-Y, Ho K-H, Chen H-C, Chien M-Y. Exercise training improves sleep quality in middle-aged and older adults with sleep problems: a systematic review. J Physiother. 2012;58(3):157-163.

40. Hartescu I, Morgan K, Stevinson CD. Increased physical activity improves sleep and mood outcomes in inactive people with insomnia: a randomized controlled trial. J Sleep Res. 2015;24(5):526-534.

41. Ohayon MM, Sagales T. Prevalence of insomnia and sleep characteristics in the general population of Spain. Sleep Med. 2010;11(10):1010-1018.

42. Leger D, Guilleminault C, Dreyfus JP, Delahaye C, Paillard M. Prevalence of insomnia in a survey of 12,778 adults in France. J Sleep Res. 2000;9(1):35-42.

43. Scaife B, Gill PS, Heywood P, Neal R. Socio-economic characteristics of adult frequent attenders in general practice: secondary analysis of data. Fam Pract. 2000;17(4):298-304.

44. Kapur N, Hunt I, Lunt M, McBeth J, Creed F, Macfarlane G. Primary care consultation predictors in men and women: a cohort study. $\mathrm{Br} J$ Gen Pract. 2005;55(511):108-113.

45. Rasu RS, Shenolikar RA, Nahata MC, Balkrishnan R. Physician and patient factors associated with the prescribing of medications for sleep difficulties that are associated with high abuse potential or are expensive: an analysis of data from the National Ambulatory Medical Care Survey for 1996-2001. Clin Ther. 2005;27(12):1970-1979.

46. Metsa-Simola N, Martikainen P. Divorce and changes in the prevalence of psychotropic medication use: a register-based longitudinal study among middle-aged Finns. Soc Sci Med. 2013;94:71-80.

47. Linjakumpu T, Hartikainen S, Klaukka T, Koponen H, Kivelä SL, Isoaho R. Psychotropics among the home-dwelling elderly-increasing trends. Int J Geriatr Psychiatry. 2002;17(9):874-883.

48. Glass J, Lanctôt KL, Herrmann N, Sproule BA, Busto UE. Sedative hypnotics in older people with insomnia: meta-analysis of risks and benefits. BMJ. 2005;331(7526):1169.

49. Victorri-Vigneau C, Gérardin M, Rousselet M, Guerlais M, GrallBronnec M, Jolliet P. An update on zolpidem abuse and dependence. $J$ Addict Dis. 2014;33(1):15-23.

50. Morin C. Psychological and behavioral treatments for insomnia I: approaches and efficacy. In: Kryger $\mathrm{MH}$, Thomas R, Dement WC, editors. Principles and Practices of Sleep Medicine. Philadelphia, PA: Elsevier/Saunders; 2011:866-883.

51. Morin CM,Benca R. Chronic insomnia. Lancet. 2012;379(9821):1129-1141.

52. Espie CA, Kyle SD, Williams C, et al. A randomized, placebo-controlled trial of online cognitive behavioral therapy for chronic insomnia disorder delivered via an automated media-rich web application. Sleep. 2012;35(6):769.
Journal of Multidisciplinary Healthcare

\section{Publish your work in this journal}

The Journal of Multidisciplinary Healthcare is an international, peerreviewed open-access journal that aims to represent and publish research in healthcare areas delivered by practitioners of different disciplines. This includes studies and reviews conducted by multidisciplinary teams as well as research which evaluates the results or conduct of such teams or health
Dovepress

care processes in general. The journal covers a very wide range of areas and welcomes submissions from practitioners at all levels, from all over the world The manuscript management system is completely online and includes a very quick and fair peer-review system. Visit http://www.dovepress.com/ testimonials.php to read real quotes from published authors. 